\title{
Paisagens em trânsito: o caso da Estrada Parque Taguatinga
}

SELECCIÓN VIII SEMINARIO INTERNACIONAL DE INVESTIGACIÓN EN URBANISMO

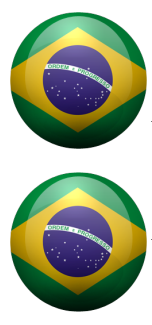

\section{Sued Ferreira da Silva}

Mestrado em Teoria, História e Crítica em Arquitetura e Urbanismo, Programa de Pós-graduação em Arquitetura e Urbanismo da Universidade de Brasília (UnB). Brasília [DF] Brasil. <ferreira.sued@gmail.com>

\section{Luciana Saboia}

Arquiteta e Urbanista pela UnB, Mestre e Doutora em Théorie et Histoire de l'Architeture et la Ville na Université Catholique de Louvain [Bélgica]. Professora da Faculdade de Arquitetura e do Programa de PósGraduação em Arquitetura e Urbanismo da UnB. Brasília [DF] Brasil. <lucianasaboia@unb.br>

\section{Resumo}

0 artigo busca investigar a experiência da paisagem no cotidiano a partir dos deslocamentos ao longo dos eixos viários, tendo como estudo de caso a Estrada Parque Taguatinga (EPTG), DF-085. A discussão irá delinear-se a partir de um componente teórico e outro empírico. 0 primeiro irá examinar o papel das infraestruturas viárias no reconhecimento do território e de suas paisagens, e principalmente os modos de percepção nos deslocamentos cotidianos e na experiência do próprio movimento. Já o componente empírico se desenvolverá em função do estudo de caso, iniciando-se com um breve histórico da via, suas escalas, usos e configurações; como também de análises baseadas na antropologia interpretativa, com as ferramentas de descrição etnográfica e observação participante, de modo a identificar tais paisagens, em permanente mutação. Além de situar as narrativas dos praticantes da cidade em seus percursos, atravessamentos e as experiências sensíveis que estabelecem com o território e a própria via no cotidiano.

\section{Palavras-chave}

Paisagem. Cotidiano. Descrição etnográfica. Estrada-parque.

\section{Landscapes in transit: the case of Park Road Taguatinga}

\begin{abstract}
This paper investigates the experience of the landscape in everyday life over mobility infrastructures through the case study Estrada Parque Taguatinga (EPTG), DF-085. The discussion has two components, one theoretical and another empirical. The first one will examine the role of the road infrastructure in recognition of the territory and its landscapes, the perception modes in daily commuting and the motion experience itself. Besides, the empirical component will be developed according to the case study, starting with a brief parkway historiography, its edges, uses and configurations; as well as analyzes based on interpretative anthropology, and its ethnographic description and participant observation tools, in order to identify those landscapes, constantly changing. Besides situating the citizens' narratives in their paths, crossings and sensitive experiences which they establish with the territory and with the parkway in the everyday life.
\end{abstract}

\section{Keywords}

Landscape. Everyday life. Ethnographic description. Parkways. 


\section{Introdução}

[...] mas não há mais terra, por isso tendemos a crescer em direção ao mar [...] As pessoas se deslocam diariamente a centro da cidade e devem regressar logo, pela tarde, a suas casas, situadas fora da cidade. 0 tempo que o homem médio necessita para esta viagem é de uma hora. [...] neste projeto, o arquiteto pensa no futuro da cidade. Dividiu-a em dois elementos, um permanente e o outro transitório. [...] O elemento estrutural é concebido como uma árvore - elemento permanente - com as unidades de habitação como folhas - elemento temporários - que caem e voltam a brotar segundo as necessidades do momento. Dentro dessa estrutura, os edifícios podem crescer, desaparecer e voltarem a crescer, mas a estrutura permanece (Tange, 1959).

As superfícies asfaltadas, as sinalizações, os ritmos do trânsito, as perspectivas previamente definidas, os enquadramentos, as paragens, o tempo, os itinerários, o intervalo entre a origem e o destino são elementos presentes no cotidiano das cidades contemporâneas, cujas percepções apresentam-se em função da rapidez, da aceleração, do transitório, das opacidades e vertigens, das metamorfoses e do caos, que vêm a caracterizar as paisagens urbanas no desenrolar de suas narrativas e deslocamentos diários, na busca da anulação das distâncias geográficas, e que serão objetos de estudo deste artigo.

Diversos autores têm discutido sobre a apreensão da cidade e de suas paisagens a partir do caminhar, aos olhos do flâneur e das múltiplas práticas que vêm a viabilizar uma nova experiência estética entre o sujeito e os espaços de vivência. Do olhar distanciado do viajante que (re)constitui paisagens a medida de seus anseios, expectativas, na busca intensa pelo novo e pelo inusitado, decifrando as particularidades e as transformações da metrópole. Mas como se dá a experiência da paisagem nos deslocamentos cotidianos? Na repetição de seus percursos? No olhar desinteressado e corriqueiro dos "praticantes ordinários da cidade" que abruma os objetos, possibilidades e irrupções da vida humana?

0 presente artigo é resultado de reflexões preliminares do projeto de Dissertação de Mestrado em Teoria, História e Crítica em Arquitetura e Urbanismo do Programa de Pesquisa e Pós-graduação em Arquitetura e Urbanismo da Universidade de Brasília sob orientação da Dra. Luciana Saboia. Tem como questões centrais a investigação da experiência das paisagens cotidianas nos deslocamentos ao longo das infraestruturas de mobilidade, a partir do caso da Estrada Parque Taguatinga (EPTG), DF 085, principal corredor de ligação do Eixo Oeste de urbanização do Distrito Federal.

Concebida inicialmente na qualidade de Estrada Parque, inspirada nas parkways americanas para resguardar o patrimônio natural, arquitetônico e urbanístico do Plano Piloto idealizado por Lúcio Costa, a EPTG tornou-se um elemento de articulação entre este e as centralidades constituintes da maior conurbação urbana do Distrito Federal: Guará, Águas Claras, Vicente Pires, Taguatinga e Ceilândia. Nos seus 56 anos de existência, passou por distintas ampliações, como a implantação de vias marginais, viadutos, pontes, passarelas, ciclovias e em 2010 foi transformada em via expressa com a denominação Linha Verde. Esta mudança de tipologia foi resultado de um processo de urbanização ao longo de suas margens, seja por ocupações irregulares ou por decisão política de produção de novos núcleos urbanos em um território disperso. Isto coloca a EPTG como um paradoxo, pois a medida que torna-se uma fronteira entre regiões administrativas, as atuais configurações da via reforçam o caráter de segregação espacial e acentuam os contrastes entre paisagens.

Estas questões irão alimentar a discussão, que estrutura-se a partir de um componente teórico e outro empírico. 0 primeiro irá examinar o papel das infraestruturas viárias no reconhecimento do território e de suas paisagens, e principalmente os modos de percepção nos deslocamentos cotidianos e na experiência do próprio movimento. Já o componente empírico se desenvolverá em função do caso da Estrada Parque Taguatinga, subdividindo-se em dois objetivos específicos: o levantamento da historiografia da via, suas escalas, usos e configurações; a leitura das paisagens lindeiras à via, em constante transformação, e a captação das narrativas dos praticantes da cidade em seus percursos, atravessamentos e nas experiências sensíveis que estabelecem com o território e com as paisagens cotidianas. 
Adotou-se dentre os referenciais teóricos uma abordagem da antropologia interpretativa, mais precisamente de descrição etnográfica e observação participante, de modo a tecer reflexões entre o imaginado, o construído e o vivido. De forma complementar, serão examinadas as propostas de levantamento da paisagem imediata e em movimento propostas por Panerai (2006, p.44) e Apleyard, Lynch e Myer (1964), por intermédio de relatos não estruturados de usuários de transporte público, as quais ajudarão a compor as imagens e desdobramentos possíveis do objeto de estudo.

\section{Paisagem e infraestruturas viárias: uma questão de movimento}

O deslocamento é o evento e se desenrola à medida que o percurso vai sendo apresentado (Dias, 2011).

A cidade contemporânea reúne em seus estratos formais, históricos e sociais contradições e ambiguidades como resultados das práticas, resquícios e transformações das formas de cidade precedentes, a cidade industrial e a cidade moderna. Um ajuntamento de fragmentos e racionalidades múltiplas que contribuíram para a sua percepção como um território de natureza instável, onde opera o caos, a desordem e a incerteza.

Para Secchi (2006, p.90), suas articulações funcionais e morfológicas em uma configuração urbana fragmentada, heterogênea e dispersa resultaram primeiramente em um movimento de liberação das ordens e linguagens da urbanística clássica construída sob aspectos unitários; e posteriormente como o próprio 'lugar da não contemporaneidade', por reunir em seu território inextricáveis temporalidades e ordenamentos nascidos do progresso das tecnologias de informação, dos sistemas de mobilidade e das reorganizações dos processos socioeconômicos.

As descontinuidades e a dilatação do tecido urbano, conseguinte do esmaecimento dos limites consolidados entre cidade e campo, engendram a formação de uma cidade de alcance regional, a cidade-território conforme denominada por Cacciari (2009, p.31), ao incorporar aglomerações de distintas formas sociais e espaciais em suas imediações. Isto vem a estabelecer novas significações da dialética centro-periferia e uma ruptura com os referenciais simbólicos tradicionais, frente ao fluxo e a velocidade das transformações culturais e de ocupação do território.

O tecido urbano prolifera, estende-se, corrói os resíduos de vida agrária. Estas palavras, o "tecido urbano", não designam, de maneira restrita, o domínio edificado nas cidades, mas o conjunto de manifestações do predomínio da cidade sobre o campo. Nessa acepção, uma segunda residência, uma rodovia, um supermercado em pleno campo, fazem parte do tecido urbano. Mais ou menos denso, mais ou menos espesso e ativo, ele poupa somente as regiões estagnadas ou arruinadas, devotas à 'natureza' (Lefebvre, 1999, p.17).

Tais questões são discutidas por Lefebvre (1991), Secchi (2009), Garreau (1991), Ascher (2010), Panerai (2006) e denominadas como dispersão urbana, Città Difusa, Edge City, Urban Sprawl, dentre outras; e passam a ser compreendidas em conjunto com os sistemas e redes de transporte e comunicação, demarcando o papel destes na viabilização da expansão urbana em direção as áreas periféricas, na formação de novos limites, núcleos urbanos secundários e estruturações espaciais. Além de permitir conexões em distintos pontos do território, modificando-os e impactando em sua organização.

Conforme exposto por Panerai (2006), a via é um suporte à urbanização desde as primeiras aglomerações urbanas, sendo determinante em sua forma e lógica ao garantir os deslocamentos, acessos, atravessamentos, paragens: "a força da relação caminho/cidade é de tal ordem que certas cidades parecem ser tão-somente uma sucessão de estradas em torno das quais se organiza o tecido urbano" (Panerai, 2006, p.18). Paralelamente, uma nova paisagem é conformada a partir das mudanças e transformações impostas pelas infraestruturas viárias no processo de ocupação do território, alterando não somente as formas de percepção, mas também de experiência. Além de impactar os idioritmos urbanos, e consequentemente as concepções de tempo e espaço, geradas em função das temporalidades e ritmos próprios dos sujeitos e grupos sociais (Secchi, 2009, p.22), a infraestruturas de mobilidade ao compor os elementos que configuram o território, determinam também sua leitura e reconhecimento. 
A velocidade, e a experiência completamente nova do movimento engendrado pela velocidade, são dois parâmetros de importância central para os séculos XIX e XX. Através deles, tudo se reorganizou: o tempo assim como o espaço, as paisagens, as cidades, o comércio e a sociedade. (Freytag apud Matos, 2013, p.132).

Isto vem a conceber uma distinta forma de olhar e pensar a paisagem e o território, os quais passam a ser compreendidos não mais a partir de um ponto fixo, mas sim no deslocamento, conformando os múltiplos pontos de vista do observador que percorre seus espaços. Anne Cauquelin (2007) e Michel Collot (2013) postulam em seus escritos que a experiência da paisagem ${ }^{1}$ esteve moldada por aspirações literárias (poesia e prosa) e por um logo período de educação estética, dado principalmente pela pintura, com a instrumentalização da perspectiva, e dos efeitos ilusórios por ela instaurados.

A delimitação de um ponto de vista único, a estruturação das cenas a partir de uma sequência de planos e de uma razão matemática, além do uso da terceira dimensão, (profundidade), organizando as figuras em torno das linhas de fuga que se direcionam ao infinito, impeliram representações imagéticas da paisagem que condicionam construções mentais e sua percepção centrada apenas no sentido do olhar. Isto vem a reafirmar o papel primordial da arte enquanto formadora de uma consciência e dos modos de apreensão da paisagem, e em contrapartida, da própria paisagem enquanto orientadora e suporte para o desenvolvimento da arte.

É no Romantismo que a paisagem deixa de ser praticada e concebida como uma construção a priori, e passa a ser apropriada pelo sujeito que nela se insere, deixando-se afetar por suas formas concretas (cores, luz, odores, sons, temperatura etc.), transpondo seu entendimento restrito a um sentido visual, cuja vivência é dada a distância, como um pano de fundo, para uma dimensão espacial, onde o corpo reside e a percebe em todos os sentidos. Esta transformação coloca a paisagem enquanto orientadora da vida humana, quando, segundo Cauquelin $(2007$, p.10) passa a dar forma, enquadramento e medida as nossas percepções e visões de mundo.

Com o desenvolvimento das tecnologias de comunicação e transporte, suprimindo distâncias geográficas e resultando em novas relações com o tempo-espaço, a experiência da paisagem se dá, primeiramente, conforme explicitado por Ana Cardoso Matos (2013), a partir de uma mudança de velocidade, pelos distintos ritmos, temporalidades, frequências, intervalos nos deslocamentos na cidade; em segundo, por uma mudança de escala, ao expandir o alcance do olhar frente aos desníveis, novas direções e a transposição de planícies, vales e montes; e finalmente por uma mudança de perspectiva, por instaurar novos pontos de vista, contínuos e descontínuos, aberturas, coexistências e representações imaginárias a partir da experiência estética e da impressão destas estruturas no território.

Em vista do que foi exposto e frente uma miríade de definições e aproximações advindas de seu caráter transdisciplinar, a paisagem então pode ser compreendida como um lugar de trânsito, rompendo com as ilusões das representações pictóricas, ao exprimir um novo modo de estar no espaço, de vivenciá-lo e percebê-lo plenamente. A paisagem e suas estruturas já não são concebidas como como um plano dado a priori, mas onde sua espacialidade constitui-se no movimento, reajustando-se em função dos deslocamentos, orientações, direções e horizontes.

\section{EPTG: um breve histórico}

Resultante de uma concepção urbanística moderna centrada nos ideais da Carta de Atenas e modelos urbanos como a Cidade-Jardim de Howard e Villa Radieuse, Brasília e sua extensão enquanto metrópole é caracterizada pela fragmentação e dispersão territorial, surgidas pela decisão política de criação das cidades-dormitório e concentração de poder na área central. Para Hollanda (2003), como uma metrópole polinucleada suas cidades-satélites reproduziram os parâmetros e determinações do modernismo clássico: "[...] malha hierarquizada, com poucos eixos de acesso; grande quantidade de superfície viária; setorização funcional; áreas públicas residuais” (Holanda, 2003), diferenciando-se

\footnotetext{
${ }^{1}$ Etimologicamente, paisagem advém da sufixação de païs (paeses, país) presente nas línguas românicas do século XV, designando "um quadro que representava uma determinada porção de um país" e registrada em 1549 como paysage, "palavra corrente entre os pintores" no dicionário de francês/ latim Estienne (Collot, 2013).
} 
apenas no que se refere as tipologias edilícias, o sistema de transporte coletivo, configuração do espaço público e uso do solo.

Para Jatobá (2010), a característica de expansão horizontalizada adotada como política de planejamento no Distrito Federal até a década de 1970 acentuou a descontinuidade urbana entre o Plano Piloto e as cidades-satélites, cuja implantação distanciada, típica de um padrão de periferização urbana, teve como justificativa a proteção da Bacia do Paranoá por meio de um cinturão verde nos limites do Plano Piloto - um anel sanitário que objetivava preservar seu patrimônio ambiental, urbanístico e arquitetônico. Em 1985, o Plano de Ocupação Territorial (POT) e, em 1987, o documento Brasília Revisitada consolidaram as propostas do Plano Estrutural de Ordenamento Territorial (PEOT) de 1977, em que se previa novas áreas de expansão urbana, como áreas institucionais e residenciais adjacentes a Taguatinga. 0 documento elaborado por Lucio Costa previa a implantação de quadras econômicas nos limites da Bacia do Paranoá, ao longo dos eixos viários, dentre elas o Conjunto Habitacional Lucio Costa às margens da EPTG, inaugurado em 1989, e posteriormente o bairro de Águas Claras, com plano urbanístico elaborado em 1982, legitimando o processo de ocupação do grande vazio urbano existente entre Taguatinga e o Guará.

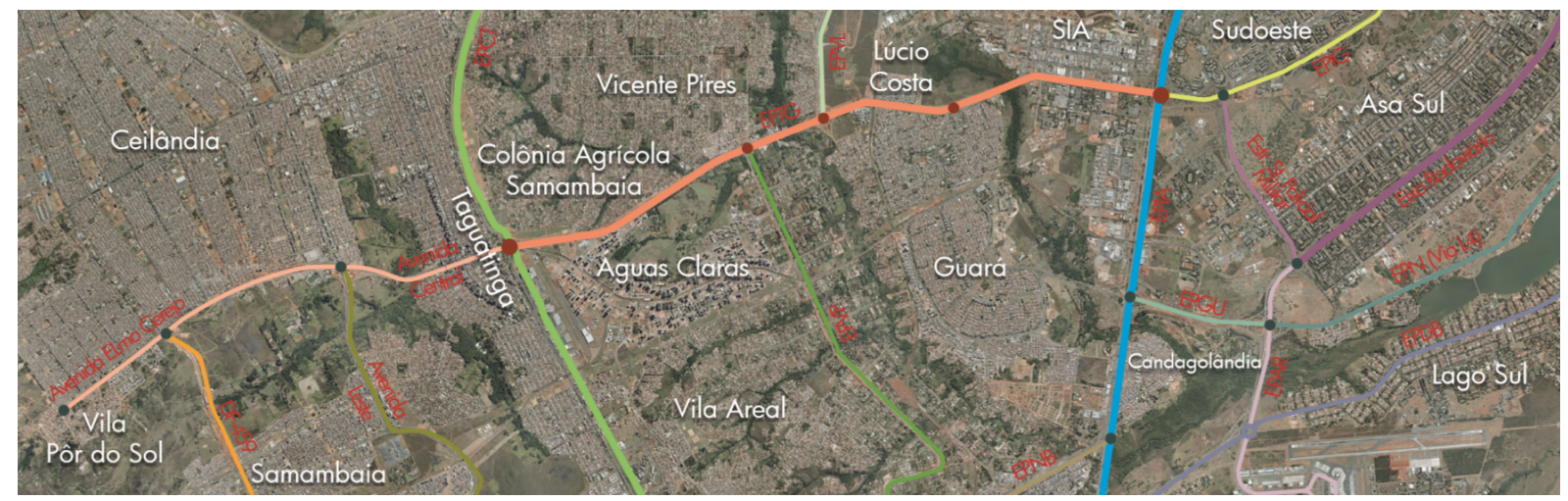

Figura 1. Sistema viário do Eixo Oeste de Urbanização. Fonte: elaboração própria.

O ideário da cidade-jardim somado a estruturação do território através de vias de trânsito rápido hierarquizadas e especializadas, denominado por Sylvia Ficher (1999) como Urbanismo Rodoviarista, foram determinantes na constituição do modelo de ocupação polinucleado. 0 sistema viário baseado em estradas-parques, aos moldes das parkways americanas, teve seu início, segundo Brito (2009), antes da implantação do Plano Rodoviário do Distrito Federal (1964) em conjunto com as obras do embrião de Brasília, em 1958 com a fundação de Taguatinga.

As primeiras estradas-parques traçadas subdividiram o território do DF em quatro quadrantes: no antigo eixo da estrada de Planaltina, a Estrada-parque Indústria e Abastecimento (EPIA), a espinha dorsal do sistema viário. Transversalmente, sobre o Anel Rodoviário, a Estrada Parque do Contorno (EPTC). A partir destas onze rodovias foram traçadas no território interno da Bacia do Paranoá, com o intuito de articular estradas federais e regionais: Estrada Parque Dom Bosco, Estrada Parque Paranoá, Estrada Parque Vicente Pires, Estrada Parque Taguatinga, Estrada Parque do Torto, Estrada Parque Península, Estrada Parque Santa Maria, Estrada Parque Acampamento, Estrada Parque do Valo, Estrada Parque Vereda Grande e Estrada Parque Ipê.

O projeto de Lúcio Costa - dominado pela justaposição de técnica rodoviária e urbanismo, que tem como determinante principal a circulação de veículos, recordando a cidade linear de Soria y Mata - respondia à intenção explícita de Kubitschek de construir uma 'cidade para o automóvel'. Esta preocupação está assinalada já no início de seu memorial, como terceira etapa da definição do plano: 'E houve o propósito de aplicar os cruzamentos - à técnica rodoviária - inclusive a eliminação de cruzamentos - à técnica urbanística, conferindo-se ao eixo arqueado [...] a função circulatória tronco, com pistas centrais de velocidade e pistas laterais, para tráfego local [...]' (Ficher apud Brito, 2009).

Criada em 1960 e com extensão aproximada de 12,7 km e um fluxo diário de 140 mil veículos, a Estrada Parque Taguatinga tem seu início na Estrada Parque Indústria e Abastecimento (EPIA) e termina 
na Estrada Parque do Contorno (EPCT), adjacente à Avenida Central de Taguatinga, estendendo-se até a Ceilândia através da Avenida Elmo Serejo. Como um dos principais eixos rodoviários ao longo eixo oeste de urbanização, conecta as Regiões Administrativas do Guará, Águas Claras, Vicente Pires, Taguatinga e Ceilândia, as quais compõem maior conurbação do Distrito Federal. Dentro do planejamento territorial estratégico do DF passou por distintas ampliações, como a implantação de vias marginais, viadutos, pontes, passarelas e ciclovias. Em 2010 foi transformada em via expressa com a denominação Linha Verde, no Programa de Transporte Urbano para a promoção da acessibilidade, mobilidade e integração dos núcleos urbanos.
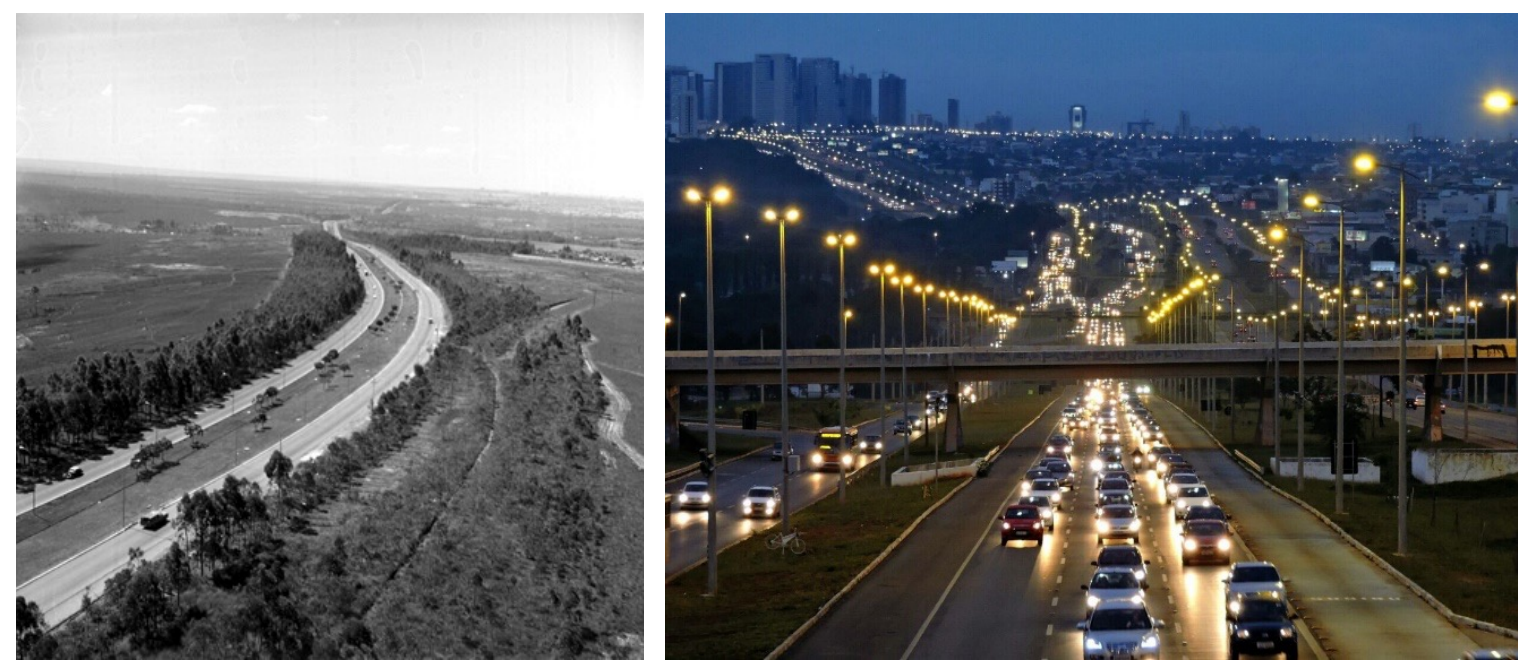

Figuras 2 e 3. À esquerda, uma imagem da EPTG em 1972. Fonte: Arquivo Público do Distrito Federal. À direita, uma imagem da EPTG atualmente. Fonte: Autor desconhecido.

Concebida inicialmente na qualidade de Estrada Parque - a ser aqui caracterizada como uma tipologia de via que busca a preservação de áreas de interesse ambiental e cultural, um corredor ecológico que garante a apreciação paisagística, o lazer e o turismo em seus percursos (Silva, 1996) - a EPTG passou a refletir em seus traçados a lógica funcionalista do urbanismo rodoviarista, criando barreiras que estabelecem rupturas de usos e escalas. Além de suscitar descontinuidades entre paisagens naturais e artificiais, vindo a impactar nas relações estabelecidas com e território e na percepção das múltiplas imagens que compõem a cidade contemporânea.

Conforme descrito no Plano Diretor de Ordenamento Territorial do DF (PDOT) do ano de 2011, a EPTG, como uma rede primária do sistema de transporte coletivo, atravessa zonas urbanas consolidadas com alta densidade demográfica, zonas rurais de uso controlado, a Reserva Ecológica do Guará e a Área de Relevante Interesse Ecológico: Parque Juscelino Kubitschek (ARIE JK), ambas inseridas na macrozona de Proteção Integral. Além disso, o PDOT/2011 ao permitir o adensamento e a concentração de atividades de comércio, habitação e serviços nas áreas limítrofes à via, busca seu posicionamento como elemento integrador e dinamizador dos espaços urbanos fragmentados que conecta, com o intuito de obter uma continuidade da mancha urbana existente e uma redução do fenômeno da dispersão do território.
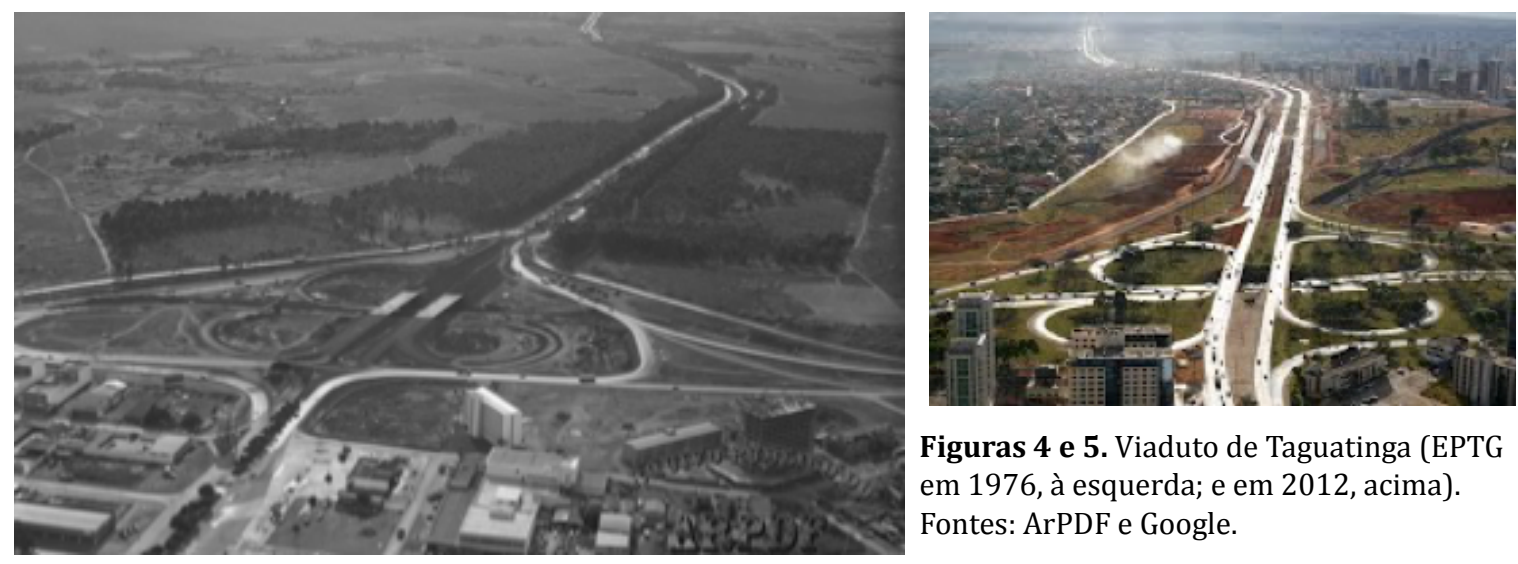

Figuras 4 e 5. Viaduto de Taguatinga (EPTG em 1976, à esquerda; e em 2012, acima). Fontes: ArPDF e Google. 
Nota-se que a EPTG representa um paradoxo, já que a paisagem idealizada das Estradas Parques perdeu seu significado diante das mutações estruturais em sua tipologia e do adensamento populacional da região a qual se insere, de modo que as soluções adotadas pelos gestores públicos, visando apenas a ampliação da capacidade viária, a transformou em um elemento de segregação sócio espacial ao reforçar a fragmentação e a descontinuidade do tecido urbano. Isto resultou em um processo amplamente denunciado pela crítica ao urbanismo rodoviarista e denominado por Jane Jacobs (1961) como erosão urbana, a qual se define pela redução do uso da via aos veículos, transformando os espaços de vivência em espaços de circulação, e como tais, imprecisos, lugares-algum, onde as referências desaparecem.

Em contrapartida, é por intermédio da própria via que a leitura do território em diferentes momentos é possível, acompanhando as transformações das paisagens circundantes e da própria história das Regiões Administrativas que tangencia. Ademais, a EPTG torna-se também uma conciliadora de polaridades em uma região repleta de complexidades e tensões entre fronteiras administrativas, áreas urbanizadas e rurais e de preservação ambiental, além de conformar localidades urbanas fabricadas pelas distintas apropriações ao longo de suas margens.

Assume-se, portanto, enquanto elemento de (re)configuração, justaposição e disjunção das paisagens intersticiais e dos fragmentos que a compõem, tornando-se um componente ativo na trama urbana. Isto vem a reforçar uma potencial capacidade de dar suporte às múltiplas leituras da paisagem e do território, nascidas nos deslocamentos cotidianos, encontros, desencontros, na solidão, na relação com o outro, nas narrativas, memórias, imaginários e no enfrentamento das questões e incertezas das experiências de mundo.

\section{Cotidiano urbano, deslocamentos e trajetos}

Solomon saith: "There is no new thing upon the earth". So that as Plato had an imagination, "that all knowledge was but remembrance"; so Solomon giveth his sentence, "that all novelty is but oblivion" (Bacon apud Borges, 1949).

Um olhar para as paisagens urbanas expressa uma busca pelos imaginários, personagens e narrativas que tecem uma complexa rede de símbolos e significados. Narrativas estas que se delineiam nos fazeres e errâncias do cotidiano, cuja experiência se dá na ordem do sentir, em perceber os detalhes banais que na repetição constante tornam-se invisíveis, e nos deslocamentos diários entre os espaços praticados. Neste sentido, para a análise que aqui se propõe, a utilização de ferramentas conceituais da antropologia interpretativa tornou-se essencial, objetivando a captação da experiência sensível da paisagem e sua multiplicidade de dimensões.

Como abordagem metodológica optou-se pela descrição de caráter etnográfico e observação participante, devido a sua capacidade de exprimir eventos, contextos, fatos, ambiências. Pela proximidade exigida àquele que observa, permitindo um diálogo cultural relevante com o objeto de estudo. Dessa forma, a análise se deu em dois momentos: o primeiro tendo como suporte a proposta de leitura da paisagem imediata de Panerai (2006, p.44) e Apleyard, Lynch e Myer (1964), as quais auxiliaram na composição de imagens-movimentos. No segundo momento, explorou-se a experiência da paisagem mediante a relatos de usuários de transporte público durante o deslocamento ao longo da EPTG, suas impressões e sensações, como também observações do contexto e de situações.

Panerai (2006) afirma que a compreensão da cidade deve partir de seu interior, em uma sucessão de deslocamentos. Uma sequência visual resultante das novas formas de olhar e representar o espaço, originárias da percepção da velocidade, do cinema, do desenvolvimento dos meios de transporte e das descobertas científicas. 0 registro das paisagens por meios de relatos, croquis, fotos, vídeos e cartografias constituem, segundo o autor, um modo de apreensão da cidade, a partir de distintos pontos de vista, que acabam por intervir no movimento do observador.

É preciso habituar-se a visões fragmentárias, perder a ilusão de tudo ver, aceitar o engarrafamento e a impossibilidade de estacionar. Memorizar aquilo que mal se teve tempo de entrever. Orientar-se e encontrar, ler mapas rodoviários, saber parar, trabalhar com amostras sem perder um entendimento de conjunto (Panerai, 2006, p.43). 
Assim propõe, primeiramente, uma análise sequencial das paisagens, fundamentada na obra de Lynch, para compreender as modificações do campo visual durante o deslocamento. Análise esta, que se dá na sucessão de planos e no reconhecimento de elementos que codificam a paisagem: relações de simetria/assimetria, abertura/fechamento, superfícies, ondulações, cortes verticais e horizontais, contornos, aproximações, acessos etc; e na disposição destes planos em sequência, conforme proposto por Apleyard, Lynch e Myer (1964), considerando as transições de um ao outro, sobreposições, rupturas e o tempo transcorrido.

Frente a condição das metrópoles, sua estruturação pelos eixos rodoviários, escalas territoriais orientadas pelas infraestruturas, e escalas locais, dadas pelas massas edificadas, o autor expõe a necessidade de um método que permita a compreensão dos conflitos existentes entre escalas e a relação de dependência das periferias com os centros urbanos. Além do reconhecimento das infraestruturas urbanas, ultrapassando seu entendimento como rupturas da paisagem, para elementos significativos que dão suporte, informam sobre o território e determinam sua leitura, aqui a ser organizada em três níveis subsequentes:

A paisagem imediata, aquela constituída pela via e suas margens, analisada a partir das variações no campo visual (Lynch), dos elementos simbólicos (Venturi), das concentrações de atividades (Demorgon). A análise pode misturar observações intuitivas; guiadas por aquilo que impressiona de modo imediato, e observações sistemáticas [...] 0 território percebido. Às vezes limitada à própria via, com margens construídas ou arborizadas impermeáveis ao olhar, a paisagem da estrada inclui, em outros momentos, intervenções de elementos longínquo, edificado ou não, entre os quais se destacam os marcos [...] $O$ território constituído historicamente, estudado cruzando-se uma primeira leitura/interpretação dos dados históricos e cartográficos com a abordagem visual e o conhecimento concreto do terreno que ela proporciona. Não se trata mais de se interessar por esta ou por aquela estrada que estrutura uma parte da aglomeração, mas de pesquisar o sistema pelo qual e organiza a aglomeração e de encontrar na ocupação atual os traços e as consequências da história (Panerai, 2006, p. 44).

Desta forma, a primeira leitura do objeto de estudo se deu de forma intuitiva tendo o cuidado de demarcar inicialmente os limites entre as distintas Regiões Administrativas. 0 deslocamento foi realizado por meio de transporte público em 7 de dezembro de 2015, tendo como ponto de origem a Rodoviária do Plano Piloto às 10:30 horas, Linha 310 Setor 0, e com destino a Praça do Relógio em Taguatinga, seguido pelo percurso de volta ao local de origem. Cada viagem durou em média 35 minutos frente a fluidez do trânsito, fora dos horários de pico, e em cada sentido, buscou-se registrar por meio de fotografias e vídeos as paisagens do lado direito da via, de modo compreender de forma mais abrangente as cenas ao longo das suas margens.

A paisagem é percebida em um plano-sequência, sem interrupções. 0 ônibus torna-se um filtro, um mediador entre o observador e o que é contemplado. Desta forma, o enquadramento das janelas e a velocidade de deslocamento limitou a captura de detalhes mais precisos, porém não deixa de ser visível os fragmentos e rupturas resultantes das transições entre zonas densamente edificadas e espaços livres e residuais, paisagens industrias (SIA), áreas comerciais (supermercados, centros comerciais, casas de festa, galpões de abastecimento, postos de gasolina), edifícios institucionais (concessionárias, faculdades, sedes administrativas) e principalmente o descortinar da paisagem em Águas Claras e Taguatinga com suas edificações em altura em contraposição a horizontalidade do amontoado de residências unifamiliares na Colônia Agrícola Samambaia, Vicente Pires e multifamiliares de 2 e 3 pavimentos no Guará.

Sounds, smells, sensations of touch and weather are all diluted in comparison with what the pedestrian experiences Vision is framed and limited, the driver is relatively inactive. He has less opportunity to stop, explore, or choose his path than does the man on foot. Only the speed, scale and grace of his movement can compensate for these limitations (Apleyard, Lynch, \& Myer, 1964).

Os elementos que compõem a infraestrutura viária como as superfícies asfaltadas, as faixas de trânsito, faixas exclusivas, pistas marginais, passarelas, viadutos, pontes, ciclovias, calçadas, paradas de ônibus, linhas de transmissão, mobiliário urbano, iluminação pública, sinalização viária 
vertical e horizontal, anúncios, taludes, muros, desníveis também foram registrados e demonstram que a mudança de tipologia de Estrada Parque para Via Expressa em 2010 agravou o sentido de esvaziamento, conforme evidenciado por Jacobs em 1961. Posto que, as vias expressas pensadas como planos padronizados e especializados para a circulação em massa, estabelecem relações distintas entre o usuário e o território, frente a necessidade de rápido acesso as diversas origens e destinos e da eliminação dos pontos de referências.

Marc Augé no livro "Não-lugares: introdução a uma antropologia da sobremodernidade" (1994), retrata este fenômeno quando define tanto as vias expressas quanto aeroportos, salas de espera, estações de metrô, campos de refugiados etc., como não-lugares, espaços de ninguém, caracterizados por não serem relacionais, históricos e identitários. Os não-lugares alteram a estrutura interna da cidade e excluem os "lugares de memória", conformando uma nova configuração sócio espacial em que o transitório, o efêmero e a solidão são as principais características. Em contraposição, descreve o espaço antropológico, que é culturalmente construído, centrado num espaço-tempo definido, capaz de criar identidades e promover de relações interpessoais.

O tempo do deslocamento, o intervalo entre a origem e o destino são determinantes, seja na configuração das vias e, por conseguinte do território, como na experiência espacial. Para Godim (2014), a rapidez e aceleração tornaram-se especificidades nas vias expressas na busca pela anulação das distâncias geográficas. A questão do tempo apresenta-se como um dos pontos focais nas narrativas coletadas durante o segundo dia de deslocamentos na EPTG via transporte público, com o intuito de compreender as percepções das paisagens, seus pontos de interesse, itinerários.

A entrevista se deu de forma não estruturada de modo a permitir ao entrevistado uma flexibilidade nas respostas, segundo suas próprias referências. A linha 314 foi escolhida para o trajeto com destino a Rodoviária do Plano Piloto, tendo como ponto de origem a Avenida Hélio Prates, CNN 01, Ceilândia em 11 de dezembro de 2015 às 07:20 horas. Os entrevistados, 6 (seis) ao todo, estavam a caminho do trabalho, em distintas localizações do Distrito Federal: Lucio Costa, SIA, Setor Policial e Asa Sul. 0 trânsito entre Ceilândia e Taguatinga apresentava uma morosidade, intensificando a preocupação diária no tempo de deslocamento, aproximadamente 1 hora a depender do destino, e nos possíveis engarrafamentos, acidentes, obras e manutenções nas vias.

Envoltos no planejamento das tarefas a realizar no dia que se iniciava, direcionavam a atenção para os dispositivos tecnológicos, para os acontecimentos do espaço interno do ônibus: faces conhecidas que se esbarram diariamente na mesma linha; prosas despretensiosas entre passageiros; sons dos motores interpelados pela fala dos vendedores ambulantes; o fluir do trânsito, o principal atrativo do olhar para além das janelas do veículo; a passagem das horas, constantemente verificada e o sono que por vezes persistia, monotonia. A paisagem não existia, anulava-se entre a origem e o destino, um percurso ladeado pelo vazio e pelas contingências cotidianas.

Quando consigo um lugar para sentar é um alívio! Nada me deixa mais irritada do que ônibus lotado! Sinto muita dor nas pernas! É desconfortável! Quando estou sentada, eu durmo até chegar na minha parada, ou fico no Facebook [...]. Nada me chama atenção no caminho [...]. Existe paisagem? (Entrevistado I, servidora pública, em 11 dez. 2015).

Não, nada... No máximo quando tem engarrafamento, eu fico olhando os carros, para ver se foi acidente, fico vendo o movimento, propaganda... (Entrevistado IV, estudante, em 11 de dez. 2015).

Percebe-se que a estrada e as perspectivas previamente definidas resultam no tolhimento do deslocar-se livre, nos ritmos do trânsito e dos itinerários impostos aos usuários assim como as vertigens de um olhar que já não identifica as faces da paisagem que os envolve: "[...] o viajante transportado torna-se um passageiro: ele próprio não se desloca, mas é deslocado dum lugar ao outro" (Ingold apud Besse, 2013, p.52).

O deslocamento e a percepção mesclam-se frente a uma paisagem que se conforma a medida do movimento do sujeito, entre idas e vindas. No ato do atravessamento os significados residem no movimento, não na materialidade de suas superfícies. Por conseguinte, ao demarcar os ritmos ao território, a paisagem tem a possibilidade de revelar-se mesmo na repetição inerente ao cotidiano, 
pois é nele que residem os seus instantes, na transfiguração do lugar comum, quando o olhar do passageiro transmuta-se no olhar do viajante.

A paisagem seria então uma maneira singular de ver no mesmo a diferença, seria o momento onde nos aproximamos dos espaços e somos enlaçados, atravessados por ele. Ela é ponto de vista, ponto de contato. Esta experiência pode ser pensada como uma fissura, como um hiato que rompe com o tempo da rotina e instala o tempo de um certo ponto de vista, o tempo de uma certa vista. É como se a cada experiência da paisagem, o espaço cotidiano repentinamente ganhasse relevo e se elevasse aos nossos olhos (Dias, 2008).

As questões tratadas neste artigo indicam horizontes ainda a serem expandidos e revelados. A exploração de ferramentas da Etnografia e do levantamento das paisagens em movimento teve o intuito de situar as narrativas dos praticantes da cidade em seus percursos e espaços cotidianos. Dessa formar, ao traçar as vivências, sentimentos, pontos de vista, memórias dos sujeitos e das relações que estabelecem com o território e a paisagem, é possível a construção de uma multiplicidade leituras, impressões e experiências reais que indicam caminhos para a apreensão de seus limites, materialidade e especificidades. Ademais, pensar a paisagem no cotidiano, significa pensar a paisagem enquanto narrativa e experiência, contribuindo para o entendimento de um conceito ainda impreciso, complexo e que permeia distintos campos do saber e por tal razão, capaz de evocar memórias, sentimentos e afetos. Uma intermediária que influencia categorias espaciais e cognitivas, tornando-se um elo para a percepção do mundo.

\section{Referências}

Apleyard, D., Lynch, K., \& Myer, J. R. (1964). The view from the road. Cambridge: Massachussetts Institute of Technology.

Augé, M. (2012). Não Lugares: introdução a uma antropologia da supermodernidade (9 ed., M. Pereira, Trad.). Campinas: Papirus.

Besse, J.-M. (2013). Estar na paisagem, habitar, caminhar. Em I. Cardoso, \& I. L. Cardoso (Ed.), Paisagem Patrimônio. Porto: Dafne.

Borges, J. (1949). O Aleph (F. Cardozo, Trad.). São Paulo: Globo S.A. . Acesso em Fevereiro de 2016.

Brito, J. D. (2009). De Plano Piloto à Metrópole: a mancha urbana de Brasília. Brasília: Universidade de Brasília.

Cacciari, M. (2010). A cidade (J. J. Serra, Trad.). Barcelona: Gustavo Gili.

Cauquelin, A. (2007). A invenção da paisagem (M. Marcionilo, Trad.). São Paulo: Martins Fontes.

Collot, M. (2013). Poética e filosofia da paisagem. Rio de Janeiro: Oficina Raquel.

Dias, K. (2008). Notas sobre a paisagem, visão e invisão. Anais do VIII Seminário Nacional de Pesquisa em Arte e Cultura Visual. Goiânia: UFG. Acesso em Fevereiro de 2016, disponível em https:// seminarioculturavisual.fav.ufg.br/up/778/o/2008.GT2_Karina_Dias.pdf

Dias, K. (2011). A prática do banal, uma aspiração paisagística. Anais do Encontro da Associação Nacional de Pesquisadores em Artes Plásticas. Rio de Janeiro: ANPAP. Acesso em Fevereiro de 2016, disponível em http://www.anpap.org.br/anais/2011/pdf/cpa/karina_dias.pdf

Ficher, S. (1999). Brasília e seu Plano Piloto. Em M. Leme, Urbanismo no Brasil: 1895-1965 (pp. 230-239). São Paulo: FUPAM.

Garreau, J. (1991). Edge City: life on the New Frontier. New York: Doubleday.

Gondim, M. F. (2014). A travessia no tempo: homens e veículos, da mitologia aos tempos modernos. Brasília: Universidade de Brasília. 
Holanda, F. R. (2003, outubro). Brasília: da Carta de Atenas à Cidade dos Muros. Seminário DOCOMOMO Brasil, São Carlos, SP, Brasil, 5. Acesso em Setembro de 2014, disponível em http://www.docomomo.org.br/seminario \%205\%20pdfs/054R.pdf

Jacobs, J. (2003). Morte e vida nas grandes cidades (C. S. Rosa, Trad.). São Paulo: Martins Fontes.

Jatobá, S. U. (2010). Brasília 50 anos: da capital a metrópole (A. Paviani, F. F. Barreto, I. C. Ferreira, L. C. Cidade, \& S. U. Jatobá, Eds.). Brasília: Universidade de Brasília.

Lefebvre, H. (1991). The production of space (D. N. Smith, Trad.). Cambridge, Oxford: Blackwell Publishing.

Matos, A. C. (2013). Paisagem, Caminho-de-Ferro e Patrimônio. Em I. L. Cardoso, Paisagem Patrimônio.

Porto: Dafne Editora.

Panerai, P. (2006). Análise Urbana (F. Leitão, Trad.). Brasília: Universidade de Brasília.

Secchi, B. (2006). Primeira lição de Urbanismo. São Paulo: Perspectiva.

Secchi, B. (2009). A cidade do Século Vinte (M. Barda, Trad.). São Paulo: Perspectiva.

Silva, L. (1996). Ecologia: manejo de áreas silvestres. Santa Maria: MMA/FNMA/FATEC.

Tange, K. (1959). Discurso de Tange no CIAM de Otterloo. Acesso em Fevereiro de 2016, disponível em http:// www.cronologiadourbanismo.ufba.br/apresentacao.php?idVerbete $=22$ 